\title{
A Study of Familial Aggregation of Habitual Constipation
}

\author{
Azizollah Yousefi ${ }^{1}$, Mahsa Taghavi Ardakan ${ }^{2}$, Shahrbanoo Nakhaei ${ }^{3}$, Mehri Najafi (iD $^{4}$ and Nasim \\ Behnoud (ib) $5,6,{ }^{*}$ \\ ${ }^{1}$ Pediatric Growth and Development Research Center, Institute of Endocrinology and Metabolism, Iran University of Medical Sciences, Tehran, Iran \\ ${ }^{2}$ Iran University of Medical Sciences, Tehran, Iran \\ ${ }^{3}$ Department of Pediatric Gastroenterology, Iran University of Medical Sciences, Tehran, Iran \\ ${ }^{4}$ Department of Pediatric Gastroenterology, Pediatrics Center of Excellence, Tehran University of Medical Sciences, Iran \\ ${ }^{5}$ Student Research Committee, Iran University of Medical Sciences, Tehran, Iran \\ ${ }^{6}$ School of Persian Medicine, Iran University of Medical Sciences, Tehran, Iran \\ "Corresponding author: Student Research Committee, School of Persian Medicine, Iran University of Medical Sciences, Tehran, Iran. Tel: +98-9125121659, Email: \\ dr.nbehnoud@gmail.com
}

Received 2019 January 27; Revised 2019 April 17; Accepted 2019 May 24.

\begin{abstract}
Background: Constipation is a frequent complication in pediatrics, most of which is habitual, comprising $25 \%$ of visits in pediatric gastroenterology clinics.

Objectives: The main object of this study was to investigate clustering of habitual constipation among families of pediatric patients. Methods: This case-control study was conducted on families of 150 children $<18$ years old with chronic habitual constipation alongside families of 150 healthy children as controls. The cases were enrolled in the study according to the Rome IV criteria for constipation. The parents and siblings were evaluated regarding constipation. Data were analyzed using SPSS-16, $\chi^{2}$ and $t$-test were used for comparison.

Results: A total of 300 children and their families participated in the study. No significant differences were found between the study and the control groups in age, sex, or BMI. However, the siblings or parents from the study group had significantly higher rates of constipation compared with the control group.

Conclusions: Considering different survey findings, a correlation between "habitual constipation" and "familial background" seems to exist in children. A clear pathophysiological explanation for this phenomenon is not yet available.
\end{abstract}

Keywords: Children, Pediatric Constupation, Familial Constupation, Familial Disease

\section{Background}

Constipation is a common complaint in the referral of patients to clinics and specialized pediatric clinics (1). Although its prevalence in children is unclear, various studies at the community level indicate that the prevalence in adults in Western and Asian countries varies from $10 \%$ to $20 \%$ and in children between 0.7 and 29.6\% (2-4). The latter group also accounts for $5 \%$ of all referrals to pediatricians and about $10 \%-25 \%$ of pediatric gastrointestinal patients. In this regard, an American study estimates health costs for children with constipation to be \$3.9 billion per year(5). Constipation is often posed as a major problem for both the patient and the family. Several factors may contribute to this problem: social and economic status, consumption of low-fiber diet, lack of mobility, lack of sufficient fluid intake, and genetic predispositions, which can set the ground for constipation $(6,7)$.

In three periods, children are susceptible to functional constipation: the time to start supplementary nutrition, the time for toilet training, and the time when the school starts. For any reason, if the child feels pain and fear during bowel movements, it causes refusal of bowel movements resulting in more fecal stiffness and consequent defective cycles and worsening constipation. Approximately $35 \%$ of children under the age of 3 years, who referred to pediatric gastroenterologist for chronic constipation, mentioned a history of refusals and problems with excretion. In $63 \%$ of children with chronic functional constipation with fecal incontinence, there was a history of painful stools. Therefore, painful bowel movements are commonly associated with chronic constipation, stiff fecal mass and fecal incontinence. As a result, early treatment of painful bowel movements in children can reduce chronic constipation, stiff fecal mass and fecal incontinence in children of school age (8-10). Studies have indicated that inappropriate diets and fast food intake can have a detrimental effect on functional constipation. However, improving the nutri- 
tion of the patient by consuming fruits, vegetables, fiber and proper water use can greatly help in the treatment of some cases of functional constipation. Some children with constipation have less calories and food intake while they more commonly present anorexia and growth disorders. Also, a high consumption of cow's milk (more than $960 \mathrm{~mL}$ per day) can slow down the bowel movement and feed the child enough, depriving them of consuming other liquids and foods that soften the stool. Another important factor affecting functional constipation is family history. Children who have family members with constipation are more likely to suffer from constipation. This can suggest the role of genetics along with environmental factors. It seems that the prevalence of constipation is higher in some families, such that about half of children with chronic constipation had a family history of constipation in some studies (11-13).

\section{Objectives}

The cause of constipation in family history, with possible contributions of genetic, environmental or nutritional factors, is not well known. Considering that the role of familial history in constipation has not yet been proven to be $100 \%$, the authors sought to further investigate the relationship between family history and functional constipation.

\section{Methods}

This case-control study was conducted by random sampling of children aged 2 - 18 years referred to the pediatric gastroenterology clinic of Hazrat-e-Rasoul and Ali-Asghar Hospitals, Tehran, in 2017. After providing explanation about different aspects of the survey and confirming confidentiality of the data and asking for permission from parents, they were qualified for the inclusion criteria. They were diagnosed with habitual constipation based on the Rome IV criteria, and treated as the case group. The Rome IV criteria in infants and children up to 4 years of age include existence of at least two of the following states for one month or longer: excretion of less than or equal to twice per week, more than or equal to one episode of incontinence after acquiring excretion training skills, history of excessive retention of feces, history of painful or stiff excretion, presence of massive stool in the rectum, and thick stool history blocking the toilet bowl. In 4 -18-year old children of evolutionary age constipation is diagnosed with existence of at least two of the following conditions for one month or longer: excretion less than or equal to twice a week, more than or equal to one incontinence episode per week, history of retention status or excessive autonomic retention of feces, history of painful or stiff excretion, large stool mass in the rectum, and history of a thick stool blocking the toilet bowl $(14,15)$. In addition, all patients who had non-functional constipation, or patients and their families who suffered from a specific disease were excluded from the study. As the control group, we took children who were referred to the pediatric gastroenterology clinic for reasons other than constipation along with their parents and siblings. A prepared questionnaire on demographic information and history of constipation in parents and siblings including age, gender, and weight was completed for each patient, and the results were compared between the two groups.

\subsection{Statistical Analysis of Data}

Data of the two groups were first analyzed by descriptive analysis using SPSS 16 software and fixing bugs. Then, both qualitative and quantitative variables in the two groups were compared using chi-square test and independent $t$-test, respectively, at a significance level of $\mathrm{P}<$ 0.05 .

\section{Results}

There were 79 (52.7\%) boys and $71(47.3 \%)$ girls in the case group, while the control group comprised 83 (55.3\%) boys and 67 (44.7\%) girls. The mean age in the case and the control group was $8.08 \pm 3.43$ and $8.53 \pm 4.52$ years respectively, the difference was not statistically significant $(\mathrm{P}=0.337)$. The mean weight in the case group was 21.03 $\pm 8.56 \mathrm{~kg}$ and in the control group $23.26 \pm 13.11 \mathrm{~kg}$, with no statistically significant difference $(\mathrm{P}=0.084)$. Also, the mean height $(114.88 \pm 18.75 \mathrm{~cm})$ in the case and control $(117.95 \pm 23.68 \mathrm{~cm})$ groups were not statistically significant $(\mathrm{P}=0.214)$. Other demographic characteristics in the study groups are presented in Table 1.

Table 2 presents the distribution of meconium excretion within the first $48 \mathrm{~h}$ of birth, history of allergies, and fecal soiling in the two groups. As can be seen, the frequency of allergy in the case and control group was equal to $39(26 \%)$ and $22(14.7 \%)$ respectively, which had a statistically significant difference $(\mathrm{P}=0.015)$; the history of allergy increased the development of habitual constipation to a value of 1.77 times. The prevalence levels of allergy to cow's milk protein in the case and control group was 23 (35.3\%) and $17(11.3 \%$ ) respectively, showing a statistically significant difference $(\mathrm{P}=0.006)$; the history of allergy to cow's milk protein increased the development of habitual constipation by 2.5 times (It should be noted that the history of allergy to cow's milk protein and meconium excretion was 


\begin{tabular}{|c|c|c|c|}
\hline Variable & Case Group $(N=150)$ & Control Group $(N=150)$ & PValue \\
\hline Age, $y$ & $8.08 \pm 3.43$ & $8.53 \pm 4.52$ & $0.337^{\mathrm{a}}$ \\
\hline Gender, No. (\%) & & & $0.728^{\mathrm{b}}$ \\
\hline Boy & $79(52.7)$ & $83(55.3)$ & \\
\hline Girl & $71(47.3)$ & $67(44.7)$ & \\
\hline Weight, kg & $21.03 \pm 8.56$ & $23.26 \pm 13.11$ & $0.084^{\mathrm{a}}$ \\
\hline Height, cm & $114.88 \pm 18.75$ & $117.95 \pm 23.68$ & $0.214^{\mathrm{a}}$ \\
\hline Body mass index (BMI) & $15.81 \pm 2.76$ & $15.19 \pm 3.77$ & $0.103^{\mathrm{a}}$ \\
\hline
\end{tabular}

${ }^{\mathrm{a}}$ Independent $t$-test

${ }^{\mathrm{b}}$ Chi-square test

obtained only by questionnaire data from the parents and no special tests were used for this issue). No significant differences were, however, found between the two groups regarding meconium excretion within the first $48 \mathrm{~h}$ of birth and fecal soiling.

Table 3 provides the frequency distribution of fathers and mothers with constipation as well as the parental relationships in the two groups. As can be observed, the frequency of fathers with constipation in the case and control groups was 31 (20.7\%) and 11 (7.3\%) respectively, indicating a statistically significant difference $(\mathrm{P}=0.001)$; the fathers' constipation increased the development of habitual constipation by 2.81 times. The frequency of mothers with constipation in the case and control groups was 27 (18\%) and 13 (8.7\%) respectively, revealing a statistically significant difference $(\mathrm{P}=0.017)$ between the case and control group; the mothers' constipation developed habitual constipation by 2.7 times. Finally, habitual constipation among related parents developed by 1.76 times.

In Table 4, the frequency distribution of brothers and sisters with constipation is presented in the two groups. As can be seen, the frequency of brothers with constipation in the case and control group was equal to 13 (29.5\%) and $3(8.1 \%)$ showing a statistically significant difference $(P$ $=0.024)$; the brothers' constipation increased the development of habitual constipation by 3.64 times. The prevalence levels of constipation in sisters in the case and control group were equal to $8(22.8 \%)$ and $5(21.7 \%)$ individuals, indicating no statistically significant difference $(\mathrm{P}=1)$; the sisters' constipation increased the development of habitual constipation by 1.5 times.

\section{Discussion}

This study investigated the relationship between habitual constipation and family history of all children with habitual constipation referred to the pediatric gastroen- terology clinic of Hazrat-e-Rasoul and Ali Asghar hospitals, Teheran, in 2017. The study material consisted of 150 children with habitual constipation as the case group and an equal number of non-affected individuals as the control group.

The present study shows that habitual constipation in children has family roots, and that the siblings and parents of these children are affected more than those of the control group. Our findings are consistent with those found in adults, indicating the existence of genetic relations in this disease.

In a similar study in Sri Lanka in $2010,15.4 \%$ of children from 10 to 16 years of age had constipation, of whom those with a positive family history had a higher prevalence (12). In another study, a positive family history was reported in $28 \%$ - 50\% of children with constipation along with its higher development in single-ovule than doubleovule twins, confirming the role of genetics in the disease development (16). In 2010, a total of 112 children and their families were studied, of which 37 were probands families (test) and 75 children and their respective family members constituted the control group. No significant differences were found between the study and the control groups in age, sex, or family size. Siblings or parents from the study group (probands) had significantly higher rates of constipation compared with the control group (30\% vs. $7 \%$ and $42 \%$ vs. $9 \%$, respectively; $\mathrm{P}=0.001$ ). The results showed that habitual constipation can occur in the family in a clustered form, and in the case of two family members affected, this risk was further intensified (17). In 2007, a study in China on 677 children and families (case group), and 591 children and families as the control group revealed that the prevalence of constipation in the parents and family members of the case group was higher than that of the control group, confirming the aggregation of family constipation in the context of genetic causes (18).

A family history of common diseases in children has 


\begin{tabular}{|c|c|c|c|c|}
\hline & Case Group, No. (\%) (N=150) & Control Group, No. (\%) (N=150) & P Value & OR $(95 \% \mathrm{CI})$ \\
\hline Meconium excretion in the first $48 \mathrm{~h}$ of birth & $142(94.7)$ & $139(92.7)$ & $0.477^{\mathrm{a}}$ & $1.02(0.96-1.08)$ \\
\hline Allergy history & $39(26)$ & $22(14.7)$ & $0.015^{\mathrm{a}}$ & $1.77(1.10-2.83)$ \\
\hline Allergy history to protein and the cow's milk & $35(23.3)$ & $17(11.3)$ & $0.006^{\mathrm{a}}$ & $2.05(1.20-3.51)$ \\
\hline Fecal soiling & $79(52.7)$ & $70(46.7)$ & $0.299^{\mathrm{a}}$ & $1.12(0.89-1.41)$ \\
\hline
\end{tabular}

${ }^{\mathrm{a}}$ Chi-square test

Table 3. Distribution of Fathers and Mothers with Constipation and Parents' Relationships in the Two Groups

\begin{tabular}{|c|c|c|c|c|}
\hline Variable & Case Group, No. (\%) $(\mathrm{N}=150)$ & Control Group, No. $(\%)(\mathrm{N}=150)$ & P Value & OR $(95 \% \mathrm{CI})$ \\
\hline Fathers contracted constipation & $31(20.7)$ & $11(7.3)$ & $0.001^{\mathrm{a}}$ & $2.82(1.47-1.08)$ \\
\hline Mothers contracted constipation & $27(18)$ & $13(8.7)$ & $0.017^{\mathrm{a}}$ & $2.07(1.11-3.86)$ \\
\hline Parents familial relationships & & & $0.013^{\mathrm{a}}$ & $1.76(1.12-2.72)$ \\
\hline Related & $44(29.3)$ & $25(16.6)$ & & \\
\hline Unrelated & $106(70.7)$ & $125(83.4)$ & & \\
\hline
\end{tabular}

${ }^{\mathrm{a}}$ Chi-square test

Table 4. Distribution of Brothers and Sisters with Constipation in the Two Groups

\begin{tabular}{|c|c|c|c|c|}
\hline Variable & Case Group, No (\%) $(\mathrm{N}=150)$ & Control Group, No. $(\%)(\mathrm{N}=150)$ & P Value & $\mathrm{OR}(95 \% \mathrm{CI})$ \\
\hline Number of brothers & $44(29.4)$ & $37(25.3)$ & & \\
\hline Bothers contracted constipation & $13(29.4)$ & $3(8.1)$ & $0.024^{\mathrm{a}}$ & $3.64(1.12-11.82)$ \\
\hline Number of sisters & $35(23.3)$ & $23(15.3)$ & & \\
\hline Sisters contracted constipation & $8(22.8)$ & $5(21.7)$ & $1^{\mathrm{a}}$ & $1.05(0.39-2.81)$ \\
\hline
\end{tabular}

${ }^{\text {a } C h i-s q u a r e ~ t e s t ~}$

also been seen in other diseases which has led to studies on genetic causes of diseases like GERD (19-21) and asthma $(22,23)$. The first familial occurrence of constipation was reported in adult patients. It was found that subjects with more family members having constipation will have higher risk of constipation. There is no scientific explanation for this, but the researchers suggest that there was a significant genetic and familial connection in patients with constipation that might have been exacerbated by environmental factors (24). A similar result in pediatric patients was achieved in the present study. Previous findings suggest that the prevalence of constipation in non-white people is more common among women than men being directly related to age (25). However, in the present study, gender and age had no effects on the results; the race factor was not investigated since the children were all white.

A limitation of our study was that no valid documents, other than a parental history, were available concerning allergy to cow's milk protein or other diseases, and other confounding factors.

\subsection{Conclusions and Recommendation}

The present study shows that habitual constipation in children has family roots and that it is more observed in the siblings and parents of these children than in the control group.

It is suggested that a similar study be conducted taking different races and other confounding factors into account. Also, a similar prospective study and patient followup can lead to more robust results. A limitation of our study was that no valid documents, other than a parental history, were available concerning allergy to cow's milk protein or other diseases, and other confounding factors. It is, therefore, recommended that these factors be addressed by more reliable methods in future studies in order to obtain more accurate records on familial constipation.

\section{Footnotes}

Authors' Contribution: Study concept and design: Azizollah Yousefi; analysis and interpretation of data: Az- 
izollah Yousefi, Mehri Najafi, Mahsa Taghavi Ardakan, and Nasim Behnoud; drafting of the manuscript: Mahsa Taghavi Ardakan, and Nasim Behnoud; critical revision of the manuscript for important intellectual content: Azizollah Yousefi, Shahrbanoo Nakhaei, Nasim Behnoud, and Mahsa Taghavi Ardakan; statistical analysis: Mahsa Taghavi Ardakan and Azizollah Yousefi.

Conflict of Interests: The authors declare that they have no competing interests.

Ethical Approval: This article is extracted from dissertation No. 2034 and approved by the Committee of Research Ethics of the Iran University of Medical Sciences.

Funding/Support: There is no financial support.

\section{References}

1. van der Wal MF, Benninga MA, Hirasing RA. The prevalence of encopresis in a multicultural population. J Pediatr Gastroenterol Nutr. 2005;40(3):345-8. doi: 10.1097/01.mpg.0000149964.77418.27. [PubMed: 15735490].

2. Rajindrajith S, Devanarayana NM, Lakmini C, Subasinghe V, de Silva DG, Benninga MA. Association between child maltreatment and constipation: A school-based survey using Rome III criteria. J Pediatr Gastroenterol Nutr. 2014;58(4):486-90. doi: 10.1097/MPG.0000000000000249. [PubMed: 24253365].

3. Loening-Baucke V. Prevalence, symptoms and outcome of constipation in infants and toddlers. J Pediatr. 2005;146(3):359-63. doi 10.1016/j.jpeds.2004.10.046. [PubMed: 15756220].

4. Chu H, Zhong L, Li H, Zhang X, Zhang J, Hou X. Epidemiology characteristics of constipation for general population, pediatric population, and elderly population in china. Gastroenterol Res Pract. 2014;2014:532734. doi: 10.1155/2014/532734. [PubMed: 25386187] [PubMed Central: PMC4216714].

5. Liem O, Harman J, Benninga M, Kelleher K, Mousa H, Di Lorenzo C. Health utilization and cost impact of childhood constipation in the United States. I Pediatr. 2009;154(2):258-62. doi: 10.1016/j.jpeds.2008.07.060. [PubMed: 18822430]

6. Koppen IJ, Lammers LA, Benninga MA, Tabbers MM. Management of functional constipation in children: Therapy in practice. Paediatr Drugs. 2015;17(5):349-60. doi: 10.1007/s40272-015-0142-4. [PubMed 26259965]. [PubMed Central: PMC4768242].

7. Koppen IJ, Velasco-Benitez CA, Benninga MA, Di Lorenzo C, Saps $M$. Is there an association between functional constipation and excessive bodyweight in children? J Pediatr. 2016;171:178-82 e1. doi: 10.1016/j.jpeds.2015.12.033. [PubMed: 26787379].

8. van den Berg MM, Benninga MA, Di Lorenzo C. Epidemiology of childhood constipation: A systematic review. Am J Gastroenterol. 2006;101(10):2401-9. doi: 10.1111/j.1572-0241.2006.00771.x. [PubMed: 17032205].

9. Mearin F, Lacy BE, Chang L, Chey WD, Lembo AJ, Simren M, et al. Bowel disorders. Gastroenterology. 2016. doi: 10.1053/j.gastro.2016.02.031 [PubMed: 27144627].

10. van Summeren J, Holtman GA, van Ommeren SC, Kollen BJ, Dekker JH, Berger MY. Bladder symptoms in children with functional constipation: A systematic review. J Pediatr Gastroenterol Nutr. 2018;67(5):55260. doi: 10.1097/MPG.0000000000002138. [PubMed: 30212423].
11. Greenwald BJ. Clinical practice guidelines for pediatric constipation. I Am Acad Nurse Pract. 2010;22(7):332-8. doi: 10.1111/j.17457599.2010.00517.x. [PubMed: 20590953].

12. Rajindrajith S, Devanarayana NM, Adhikari C, Pannala W, Benninga MA. Constipation in children: An epidemiological study in Sri Lanka using Rome III criteria. Arch Dis Child. 2012;97(1):43-5. doi: 10.1136/adc.2009.173716. [PubMed: 20573735].

13. Pensabene L, Salvatore S, D'Auria E, Parisi F, Concolino D, Borrelli $\mathrm{O}$, et al. Cow's milk protein allergy in infancy: A risk factor for functional gastrointestinal disorders in children? Nutrients. 2018;10(11). doi: 10.3390/nu10111716. [PubMed: 30423934]. [PubMed Central: PMC6265683].

14. Hyman PE, Milla PJ, Benninga MA, Davidson GP, Fleisher DF, Taminiau J. Childhood functional gastrointestinal disorders: Neonate/toddler. Gastroenterology. 2006;130(5):1519-26. doi: 10.1053/j.gastro.2005.11.065. [PubMed: 16678565].

15. Rasquin A, Di Lorenzo C, Forbes D, Guiraldes E, Hyams JS, Staiano A, et al. Childhood functional gastrointestinal disorders: Child/adolescent. Gastroenterology. 2006;130(5):1527-37. doi: 10.1053/j.gastro.2005.08.063. [PubMed: 16678566].

16. Morris-Yates A, Talley NJ, Boyce PM, Nandurkar S, Andrews G. Evidence of a genetic contribution to functional bowel disorder. Am J Gastroenterol. 1998;93(8):1311-7. doi: 10.1111/j.1572-0241.1998.440_j.x. [PubMed: 9707057].

17. Ostwani W, Dolan J, Elitsur Y. Familial clustering of habitual constipation: A prospective study in children from West Virginia.J Pediatr Gastroenterol Nutr. 2010;50(3):287-9. doi: 10.1097/MPG.0b013e3181a0a595. [PubMed: 19668012].

18. Cheng C, Chan AO, Hui WM, Lam SK. Coping strategies, illness perception, anxiety and depression of patients with idiopathic constipation: A population-based study. Aliment Pharmacol Ther. 2003;18(3):319-26. [PubMed: 12895216].

19. Caffarelli C, Mauro DD, Garrubba M, Mastrorilli C. Allergy in children with functional constipation and irritable bowel syndrome. Iran J Pediatr. 2016;26(6). doi: 10.5812/ijp.5206.

20. Baran M, Cagan Appak Y, Karakoyun M, Yalcinkaya S, Eliacik K, Dundar BN. The overlap of gastroesophageal reflux disease and functional constipation in children: The efficacy of constipation treatment. Eur J Gastroenterol Hepatol. 2017;29(11):1264-8. doi: 10.1097/MEG.0000000000000979. [PubMed: 28914696].

21. Mohammed I, Cherkas LF, Riley SA, Spector TD, Trudgill NJ. Genetic influences in gastro-oesophageal reflux disease: A twin study. Gut. 2003;52(8):1085-9. doi:10.1136/gut.52.8.1085. [PubMed: 12865263]. [PubMed Central: PMC1773757].

22. Caffarelli C, Coscia A, Baldi F, Borghi A, Capra L, Cazzato S, et al. Characterization of irritable bowel syndrome and constipation in children with allergic diseases. Eur J Pediatr. 2007;166(12):1245-52. doi: 10.1007/s00431-006-0410-y. [PubMed: 17345097].

23. Van Eerdewegh P, Little RD, Dupuis J, Del Mastro RG, Falls K, Simon J, et al. Association of the ADAM33 gene with asthma and bronchial hyperresponsiveness. Nature. 2002;418(6896):426-30. doi:10.1038/nature00878. [PubMed: 12110844].

24. Chan AO, Hui WM, Lam KF, Leung G, Yuen MF, Lam SK, et al. Familial aggregation in constipated subjects in a tertiary referral center. Am J Gastroenterol.2007;102(1):149-52.doi:10.1111/j.1572-0241.2006.00886.x. [PubMed: 17037990].

25. Higgins PD, Johanson JF. Epidemiology of constipation in North America: A systematic review. Am J Gastroenterol. 2004;99(4):750-9. doi: 10.1111/j.1572-0241.2004.04114.x. [PubMed: 15089911]. 